\title{
Development of Hydrogen Peroxide Monopropellant Rockets
}

\author{
Angelo Cervone ${ }^{*}$, Lucio Torre ${ }^{\dagger}$, Luca d'Agostino \\ ALTA S.p.A. - Via Gherardesca, 5 - 56121 Ospedaletto, Pisa, Italy \\ Antony J. Musker ${ }^{\S}$ \\ DELTACAT Limited, Lee on Solent, PO13 9AU, UK \\ Graham T. Roberts** \\ School of Engineering Sciences, University of Southampton, SO17 1BJ, UK \\ Cristina Bramanti ${ }^{\dagger \dagger}$, Giorgio Saccoccia ${ }^{\ddagger}$ \\ ESA-ESTEC, Keplerlaan 1, Nordwijk, The Netherlands
}

\begin{abstract}
Alta S.p.A. (Italy) and DELTACAT Ltd. (United Kingdom) are conducting a study, funded by the European Space Agency, into the development of hydrogen peroxide monopropellant thrusters using advanced catalytic beds. The present paper focuses on the design of two different demonstration thrusters with nominal ratings of $5 \mathrm{~N}$ and $25 \mathrm{~N}$. Design requirements and specifications are presented, followed by the main results of a concept study, which was conducted to define the approximate dimensions needed. Some details about the specific design of the two prototypes and the choice of the main components are provided, with particular regard to the sensors and transducers to be used during the experimentation. Different catalytic bed configurations, including pure silver gauzes and pellets coated with manganese oxide or platinum, are going to be tested in the prototype thrusters, in order to find the optimum one for further industrial development. A dedicated test bench, designed and realized by Alta S.p.A. for tests on the thruster prototypes, is also illustrated.
\end{abstract}

\section{Nomenclature}

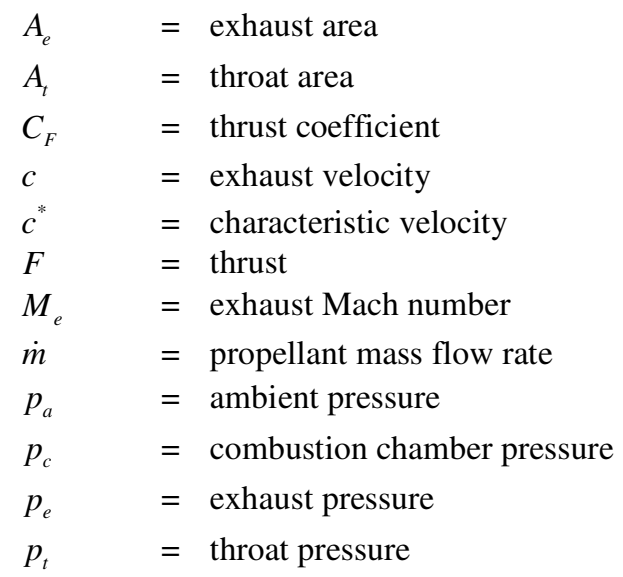

\footnotetext{
*Project manager, ALTA S.p.A., AIAA Member; a.cervone@ alta-space.com.

${ }^{\dagger}$ Project engineer, ALTA S.p.A., AIAA Member; 1.torre@alta-space.com.

* Professor, Department of Aerospace Engineering - University of Pisa, AIAA Member; luca.dagostino@ing.unipi.it.

${ }^{\S}$ Director, DELTACAT Ltd., Senior Fellow of the University of Southampton, AIAA Member; tony.musker@ deltacatuk.com.

${ }^{* *}$ Senior Lecturer, School of Engineering Sciences, University of Southampton, United Kingdom; gtr@ soton.ac.uk

${ }^{\dagger \dagger}$ Post-Doctoral Fellow, ESA Advanced Concepts Team, AIAA member; Cristina.Bramanti@esa.int.

* Head of Propulsion \& Aerothermodynamics Division, ESA-ESTEC, AIAA Member; Giorgio.Saccoccia@ esa.int.
} 


$\begin{array}{ll}R & =\text { gas constant of the exhaust gases } \\ T_{c} & =\text { combustion chamber temperature } \\ T_{e} & =\text { exhaust temperature } \\ T_{t} & =\text { throat temperature } \\ u_{t} & =\text { throat velocity } \\ \gamma & =\text { specific heat ratio of the exhaust gases } \\ \rho_{e} & =\text { exhaust density } \\ \rho_{t} & =\text { throat density }\end{array}$

\section{Introduction}

$\mathrm{L}^{\mathrm{o}}$

OW-toxicity storable liquid propellants have become considerably more attractive as possible substitutes for oxides of nitrogen and hydrazines. The main benefit of these alternative propellants is the significant cost saving associated with the drastic simplification of the health and safety protection procedures necessary during propellant production, storage and handling.

The most promising high-energy green propellants, like ADN, HAN and HNF (Wucherer et al. ${ }^{1}$, Schoyer et al. ${ }^{2}$ ), are based on complex organic molecules and compensate the large molecular weight of their decomposition products with high operational temperatures of the exhaust gases. As a consequence, it is necessary to use extremely expensive materials and manufacturing processes for the thrust chamber and, at the same time, the operational life of the catalytic beds is drastically reduced. Hydrogen peroxide, on the other hand, does not suffer from these disadvantages and has therefore been reconsidered as a promising green propellant for low and medium thrust applications.

Hydrogen peroxide is a high density liquid having the characteristic of being able to decompose exothermically into water (steam) and oxygen according to the reaction:

$$
\mathrm{H}_{2} \mathrm{O}_{2}(l) \rightarrow \mathrm{H}_{2} \mathrm{O}(\mathrm{g})+\frac{1}{2} \mathrm{O}_{2}(g)
$$

The physical properties of hydrogen peroxide are close to those of water, with two notable differences: $\mathrm{H}_{2} \mathrm{O}_{2}$ has a significantly higher density and a much lower vapor pressure. It remains in the liquid state at ambient pressure in a wide range of temperatures and is relatively easy to handle with respect to other common liquid rocket propellant oxidizers like dinitrogen tetroxide, nitric acid and liquid oxygen (Ventura and Muellens ${ }^{3}$ ). The propulsive performance of hydrogen peroxide monopropellant rockets is about $20 \%$ lower than hydrazine, but the volume specific impulse achievable with $90 \% \mathrm{H}_{2} \mathrm{O}_{2}$ is higher than most other propellants due to its high density. This is particularly useful for systems with significant aerodynamic drag losses and/or stringent volume constraints. With respect to bi-propellant and hybrid rocket engines, hydrogen peroxide yields a specific impulse comparable to other liquid oxidizers like dinitrogen tetroxide, nitric acid and even liquid oxygen (Wernimont and Muellens ${ }^{4}$, Wernimont and Garboden ${ }^{5}$ ).

The most significant technology challenge for the realization of hydrogen peroxide monopropellant thrusters is the development of effective, reliable, long-lived catalytic beds, giving fast and repeatable performance, insensitivity to poisoning by the stabilizers and impurities contained in the propellant, capable of sustaining the large number of thermal cycles imposed by typical mission profiles and not requiring (if possible) pre-heating for efficient operation. Nowadays the most frequently used catalyst materials for $\mathrm{H}_{2} \mathrm{O}_{2}$ are metallic silver, permanganates of alkali metals (Musker $\left.{ }^{6}\right)$, manganese oxides like manganese dioxide $\left(\mathrm{MnO}_{2}\right)$ and dimanganese trioxide $\left(\mathrm{Mn}_{2} \mathrm{O}_{3}\right)$.

The earliest research on hydrogen peroxide-based rockets was conducted by Walter ${ }^{7}$ in Germany during the 1930s. He invented the idea of using a catalytic bed to generate a hot stream of oxygen and steam, which could either be directed towards an exhaust nozzle or used to auto-ignite a fuel. These early engines were used in the ME163 fighter plane and to drive the V2 turbine pump. Interest in hydrogen peroxide in the post-war years up to about 1955 was confined largely to the United Kingdom, although both the United States and the former Soviet Union developed the Walter concept for different applications. The US X-1 and X-15 space planes, together with the early Mercury and Gemini manned spacecrafts, used hydrogen peroxide in their reaction control systems. Following these early developments, a significant amount of work was carried out in the 1960s at NASA laboratories on hydrogen peroxide decomposition and its application to monopropellant rockets ${ }^{8,9}$ but this effort was subsequently abandoned with the advent of effective hydrazine catalysts. On the other hand, the Russian Soyuz launch vehicle, 
which has been in active service for over forty years, continues to rely on hydrogen peroxide in its gas generator to drive the main turbine pump and in the RCS thrusters used for the descent phase.

Much of the British work on hydrogen peroxide (Rothmund \& Harlow ${ }^{10}$ ) was concerned with rocket-assisted take-off engines for rapid ascent and short runways. This led to several production engines including the monopropellant De Havilland Sprite and the Screamer, dating back to 1956. Between 1953 and 1957 the British company, Saunders Roe, developed a high performance bi-propellant peroxide engine, known as the Spectre. This was used in test-flights of the British jet fighter SR-53. The highly reliable Gamma 301 engine, developed by Bristol Siddeley in the 1950s, was used for both the first and second stages of the Black Arrow satellite launcher, which flew from Woomera, Australia in 1971. This engine provided a vacuum specific impulse of 265 seconds and used hydrogen peroxide at a concentration of $86 \%$.

In the last decade there has been a renewed interest in hydrogen peroxide engines, generated mainly by the need for less toxic propellants. However, with the exception of a very few research engines, this has not yet led to any new flight hardware. Sellers et al. ${ }^{11}$ describe their progress in the development of an efficient catalyst bed to be used in a hybrid engine. Whitehead ${ }^{12}$ illustrates the development work of small monopropellant satellite thrusters using hydrogen peroxide, carried out in 1997 at the Lawrence Livermore National Laboratory in the United States. 85\% hydrogen peroxide was used. A lightweight thruster was successfully flown in a $25 \mathrm{~kg}$ satellite and worked flawlessly with a total propellant throughput of $3.5 \mathrm{~kg}$.

In the last decade, a significant amount of work in the development, realization and flight qualification of catalytic beds for hydrogen peroxide rockets has been carried out by General Kinetics. Wernimont \& Muellens ${ }^{4}$ present some of the characteristics of the monopropellant thrusters and gas generators produced by this company. Thrusters of three different sizes are shown: 3-lbf, 6-lbf and 25-1bf. In all these cases, the catalytic beds are composed of silver screens and designed to operate with peroxide concentrations up to $92 \%$. Ventura \& Wernimont ${ }^{13}$ also illustrated some technology issues related to $98 \%$ HP catalytic beds.

Finally, studies undertaken by the Russian Scientific Center "Applied Chemistry" (RSC-AC) employed monopropellant hydrogen peroxide thrust chambers of different sizes (see Iarochenko \& Dedic ${ }^{14}$ ) in the $75 \mathrm{~N}$ to 150 $\mathrm{N}$ thrust range.

As a direct consequence of the renewed interest in the use of hydrogen peroxide shown by the rocket propulsion community, Alta S.p.A. (Italy) and DELTACAT Ltd. (United Kingdom) are carrying out a joint activity for the development of hydrogen peroxide monopropellant thrusters based on the use of advanced catalytic beds. This activity is funded by the European Space Agency in the framework of the LET-SME program, related to innovative projects carried out by small and medium European companies. The objective of the activity is the design and realization of two prototype thrusters (a $5 \mathrm{~N}$ and a $25 \mathrm{~N}$ one), in which catalytic beds made of different catalyst materials and substrates will be installed and assessed.

The present paper will illustrate the design of the prototype thrusters (including the corresponding requirements and specifications), the test bench realized for the experimentation and the preliminary test schedule foreseen in the framework of the above activity.

\section{Requirements and Specifications}

The first step in the design of the prototype thrusters was the definition of the design requirements and specifications. The following guidelines were considered to this purpose:

- Results of literature overview of thrust chambers and catalytic beds for hydrogen peroxide monopropellant rockets (including a preliminary trade-off of catalytic bed technologies and thruster technologies);

- Information obtained by past hydrogen peroxide rocket designs;

- Other considerations driven by costs reduction and safety for the operators.

After careful assessment, it was decided to proceed with the design of two different prototype thrusters, operating at $5 \mathrm{~N}$ and $25 \mathrm{~N}$, in order to explore two significantly different thrust levels. 
Table 1. Main preliminary requirements and specifications for the prototype thrusters.

\begin{tabular}{|c|c|}
\hline Optimum thrust & $5 \mathrm{~N}, 25 \mathrm{~N}$ \\
\hline Total impulse & $10000 \mathrm{~N}^{*}$ sec \\
\hline Optimum specific impulse & $140 \mathrm{sec}$ \\
\hline $\mathrm{H}_{2} \mathrm{O}_{2}$ weight concentration & $87.5 \%$ \\
\hline Minimum number of thermal cycles & 10 \\
\hline Minimum number of burnings & 1000 \\
\hline Thrust repeatability & $3 \%$ \\
\hline Minimum duration of thrust impulse & $1 \mathrm{sec}$ \\
\hline Propellant temperature range & $0 \div 50{ }^{\circ} \mathrm{C}$ \\
\hline Combustion chamber pressure & 10 bar \\
\hline Catalytic bed loading & $50 \mathrm{~kg} /\left(\sec ^{*} \mathrm{~m}^{2}\right)$ \\
\hline Liquid residence time & $0.2 \div 0.5 \mathrm{sec}$ \\
\hline Gas residence time & $1 \div 2$ msec \\
\hline Catalytic bed pre-heating & NO \\
\hline
\end{tabular}

The propellant for which the thrusters have been specifically designed is PROPULSE 875 HTP hydrogen peroxide, produced by Degussa. PROPULSE 875 HTP is a high-concentration (87.5\%) hydrogen peroxide solution, stable and relatively easyhandling, with a significantly low content of impurities and stabilizers.

With regard to operating pressures, a nominal operating pressure of approximately 10 bar has been chosen for the combustion chamber, taking into account the typical values used in similar applications in the past. The nozzle has been designed considering an exhaust pressure of $13800 \mathrm{~Pa}$ (or $2 \mathrm{psi}$ ).

The target values for the residence times have been chosen in order to be sufficiently long to allow a complete and effective decomposition of the propellant in the catalytic bed. The target value of the catalytic bed loading has been chosen near the lowest limit of the range of values typically used in the past.

Finally, the nozzle geometry (in particular the convergent/divergent angles and the fillet radius) has been defined following the typical values used for conical nozzles. The main preliminary specifications of the prototype thrusters are summarized in Table 1.

\section{Prototype Design}

Starting from the specifications highlighted in the previous Section, preliminary dimensioning of the prototype thrusters has been carried out using simplified isentropic mono-dimensional relations, which will be briefly illustrated in the following.

The combustion chamber temperature can be evaluated using the classical reaction enthalpy balance equations or, as an alternative, one of the several available software tools for chemical equilibrium calculations. The specific heat ratio and the molecular weight of the exhaust gases are evaluated in a similar way. Then, the characteristic velocity of the propellant is calculated by means of the classical equation:

$$
c^{*}=\sqrt{\frac{R T_{c}}{\gamma}}\left(\frac{\gamma+1}{2}\right)^{\frac{\gamma+1}{2(\gamma-1)}}
$$

where $T_{c}$ is the combustion chamber temperature, $\gamma$ is the specific heat ratio of the exhaust gases and $R$ is their gas constant (which, in turn, is a function of the molecular weight).

According to the frozen-flow approximation, the throat temperature $\left(T_{t}\right)$, pressure $\left(p_{t}\right)$, density $\left(\rho_{t}\right)$ and velocity $\left(u_{t}\right)$ are given by the following relations:

$$
T_{t}=T_{c}\left(\frac{2}{\gamma+1}\right) \quad p_{t}=p_{c}\left(\frac{2}{\gamma+1}\right)^{\frac{\gamma}{\gamma-1}} \quad \rho_{t}=\frac{p_{t}}{R T_{t}} \quad u_{t}=\sqrt{\gamma R T_{t}}
$$

where $p_{c}$ is the combustion chamber pressure. Exhaust Mach number $\left(M_{e}\right)$, temperature $\left(T_{e}\right)$ and density $\left(\rho_{e}\right)$ are calculated using the relations:

$$
M_{e}=\sqrt{\frac{2}{\gamma-1}\left[\left(\frac{p_{c}}{p_{e}}\right)^{(\gamma-1) / \gamma}-1\right]} \quad T_{e}=T_{c} /\left(1+\frac{\gamma-1}{2} M_{e}^{2}\right) \quad \rho_{e}=\frac{p_{e}}{R T_{e}}
$$

where $p_{e}$ is the exhaust pressure. Then, isentropic nozzle equations give the possibility of calculating the exhaust/throat area ratio and the thrust coefficient: 


$$
\begin{gathered}
\frac{A_{e}}{A_{t}}=\frac{1}{M_{e}}\left[\frac{2}{\gamma+1}\left(1+\frac{\gamma-1}{2} M_{e}^{2}\right)\right]^{(\gamma+1) / 2(\gamma-1)} \\
C_{F}=\gamma \sqrt{\left(\frac{2}{\gamma+1}\right)^{\frac{\gamma+1}{\gamma-1}} \frac{2}{\gamma-1}\left[1-\left(\frac{p_{e}}{p_{c}}\right)^{\gamma-1 / \gamma}\right]}+\left(\frac{p_{e}-p_{a}}{p_{c}}\right) \frac{A_{e}}{A_{t}}
\end{gathered}
$$

where $p_{a}$ is the ambient pressure. Finally the exhaust velocity, throat area and propellant mass flow rate are given by the following equations:

$$
c=C_{F} c^{*} \quad A_{t}=\frac{F}{C_{F} p_{c}} \quad \dot{m}=\frac{p_{c} A_{t}}{c^{*}}
$$

where $F$ is the required thrust.

The main performance characteristics of the two prototype thrusters, evaluated by means of the above simplified equations, are provided in Table 2. In this Table the "corrected" thrust (evaluated taking into account the effects of the displacement thickness at the throat) is also indicated, together with an estimation of the pressure drop across the catalytic bed, carried out using a simplified model based on the equations for the pressure drop across a porous medium.

Three-dimensional models of the two prototype thrusters, based on the design obtained by the above procedure, are presented in Figure 1. Figure 2, on the other hand, shows a cut-off drawing of the $25 \mathrm{~N}$ thruster, highlighting its main components.

The main guidelines in the design of the prototypes have been the following:

- The thrusters have been designed in a modular manner, i.e. the nozzle, the catalytic bed and the connecting flange are separate components and each one of them can be substituted without changing the others.

- Two static pressure taps are present in each thruster, one at the catalytic bed inlet and the other at its outlet. One temperature and one dynamic pressure tap are designed at the catalytic bed outlet.

- Sealing has been assured by means of coppercoated, inconel C-rings.

- Because of the moderately high value of the combustion chamber temperature (see Table 2), the engine thrust chamber and nozzle do not require the use of rare materials like Iridiumcoated Rhenium or Niobium. For this reason, the material of all the non-catalytic components is the relatively inexpensive and easily machinable AISI

Table 2. Main performance characteristics of the

\begin{tabular}{|c|c|c|}
\hline Thrust & $5 \mathrm{~N}$ & $25 \mathrm{~N}$ \\
\hline Combustion chamber temperature $(\mathrm{K})$ & 952 & 952 \\
\hline$\gamma$, exhaust gases & 1.285 & 1.285 \\
\hline Characteristic velocity, $c^{*}(\mathrm{~m} / \mathrm{sec})$ & 903.51 & 903.51 \\
\hline Combustion chamber pressure, absolute (bar) & 10.06 & 9.92 \\
\hline Exhaust Mach number & 3.33 & 3.34 \\
\hline Exhaust temperature $(\mathrm{K})$ & 369 & 367 \\
\hline Exhaust/throat area ratio $\left(A_{e} / A_{t}\right)$ & 7.841 & 7.965 \\
\hline Thrust coefficient $\left(C_{T}\right)$ & 1.561 & 1.564 \\
\hline Exhaust velocity $(\mathrm{m} / \mathrm{sec})$ & 1411 & 1413 \\
\hline Specific impulse (sec) & 143.8 & 144 \\
\hline Mass flow rate $(g / \mathrm{sec})$ & 3.544 & 17.693 \\
\hline Liquid residence time (sec) & 0.263 & 0.432 \\
\hline Gas residence time (msec) & 1.084 & 1.784 \\
\hline Corrected thrust $(\mathrm{N})$ & 4.83 & 24.145 \\
\hline Catalytic bed pressure drop (bar) & 2.5 & 1.62 \\
\hline
\end{tabular}
prototype thrusters, evaluated by means of simplified isentropic relations. 316L stainless steel.

A more detailed description of some design aspects of the thruster components is given in the next Sections. 

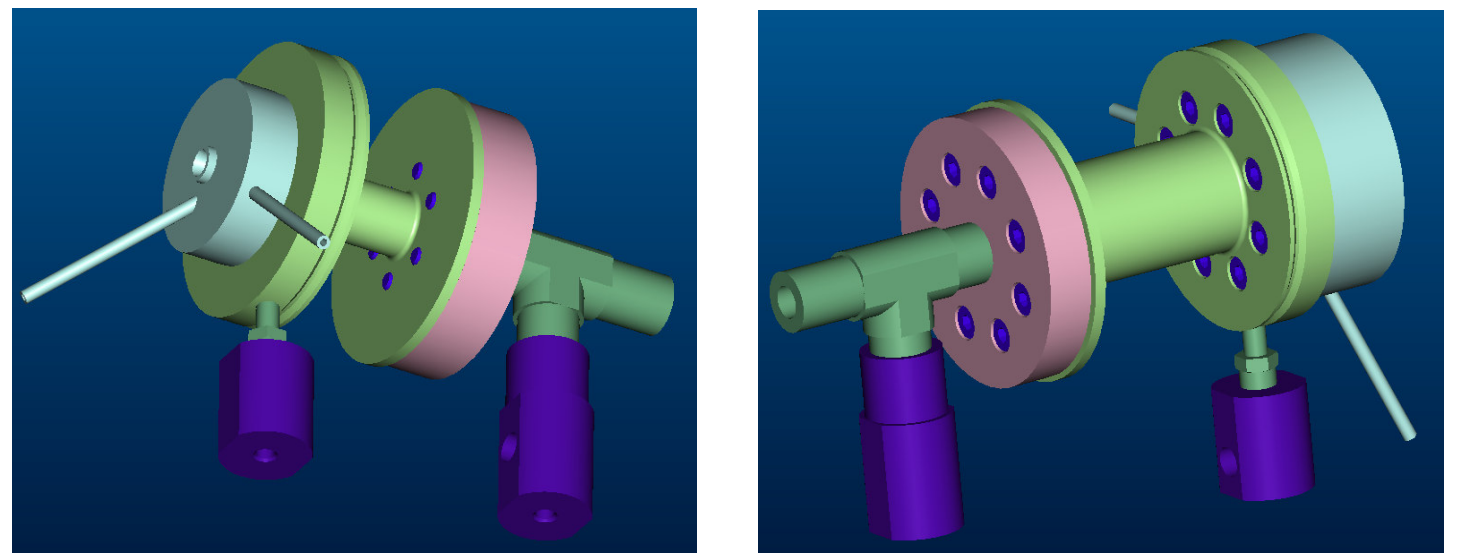

Figure 1. Three-dimensional drawings of the $5 \mathrm{~N}$ (left) and the $25 \mathrm{~N}$ thruster (right).

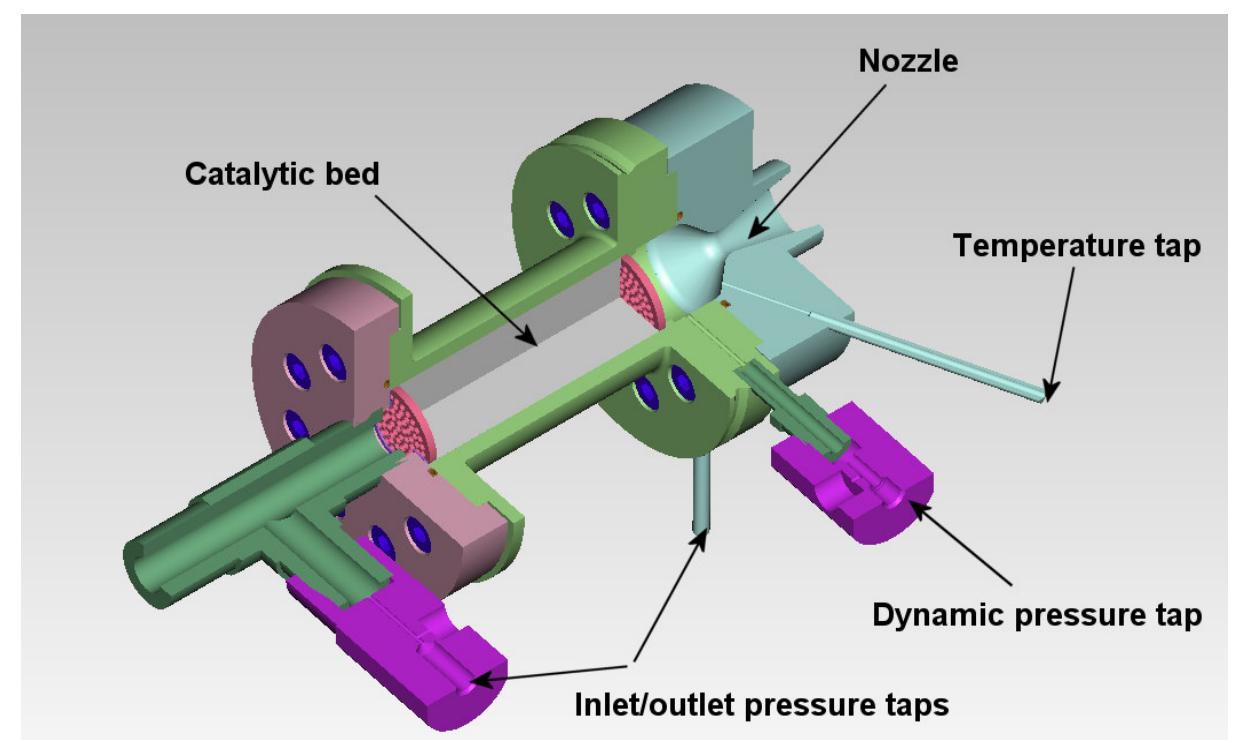

Figure 2. Cut-off drawing of the $25 \mathrm{~N}$ thruster.

\section{A. Nozzle}

The external walls of the convergent/divergent section have been made cylindrical for simplicity reasons, considering that there are no mass requirements at the present prototype stage. The dimensioning of the joining flange has been driven mainly by the interface dimensions of the C-ring seals. The pressure and temperature taps have been recessed with respect to the measurement points.

\section{B. Catalytic bed}

The catalytic bed is installed as a unique "cartridge" and joined to the other components of the prototype thruster by means of flanges. Different catalytic bed cartridges, for example with different lengths or catalyst geometry, can be installed in the prototype using the same nozzle and connecting flange.

This conceptual solution has the interesting advantage of being adaptable to different catalyst geometries, like gauzes or pellets. The bed configurations to be tested are the following:

- Pure silver grids, obtained by a 80 mesh gauze woven from a $0.115 \mathrm{~mm}$ diameter wire. In this case, some gauzes with greater wire diameter (made of silver or nickel) are alternated with the more active ones, in order to provide sufficient mechanical strength to the bed.

- Alternation of different metallic gauzes. 
- Commercially available manganese oxide-covered pellets.

- Self-impregnated manganese oxide pellets (on ceramic substrate). A technique is under development by Alta S.p.A., in collaboration with the Department of Chemistry of the University of Pisa, for the impregnation and calcination of high contact surface (up to $300 \mathrm{~m}^{2} / \mathrm{g}$ ) spheres made of Alumina- $\gamma$, using particular organic compounds as promoters. The diameter of the spheres is between 0.5 and $1 \mathrm{~mm}$ and, as a consequence, retaining grids are needed at the beginning and the end of the catalytic bed to avoid loss of the spheres in the flow through the distribution plate. The same calcination technique can also be applied to platinum-covered spheres, which are being used as another possible catalyst material for the tests.

More complex bed casing configurations are currently under design, including the possibility of measuring temperature at various stations along the catalytic bed by means of suitably designed ports and the insertion of interstitial elements of suitable form between the screen or pellets catalysts, in order to prevent possible problems due to channeling effects.

\section{Injection/distribution plates}

The main characteristics of the injection and distribution plates are summarized in Table 3 . An open area ratio of about 0.5 has been chosen for both the prototypes. Considering $1.5 \mathrm{~mm}$ diameter holes, this leads to an 18-holes plate for the $5 \mathrm{~N}$ prototype and a 92-holes plate for the $25 \mathrm{~N}$ prototype. The plate thickness has been chosen to be 1.5 $\mathrm{mm}$. Considering the really low estimated values of the pressure drop across the plates, the distribution plate has been designed equal to the injection plate (differently from what is typically observed in larger-size thrusters, where the distribution plate has normally a wider open area ratio than the injection plate).

\section{Connection to the thruster valve}

Table 3. Dimensioning and analysis of the injection/distribution plates.

\begin{tabular}{|l|c|c|}
\hline \multicolumn{1}{r|}{ Thrust } & $\mathbf{5 ~ N}$ & $\mathbf{2 5 ~ N}$ \\
\hline Open area / Total area ratio & 0.5 & 0.507 \\
\hline Diameter of holes & $1.5 \mathrm{~mm}$ & $1.5 \mathrm{~mm}$ \\
\hline Number of holes & 18 & 92 \\
\hline Estimated pressure drop (inj. plate) & $2.2^{*} 10^{-5} \mathrm{bar}$ & $2.1^{*} 10^{-5} \mathrm{bar}$ \\
\hline Estimated pressure drop (distr. plate) & $0.011 \mathrm{bar}$ & $0.1 \mathrm{bar}$ \\
\hline
\end{tabular}

The connecting flange (pink element in Figures 1 and 2) is designed in order to match the interface dimensions of the catalytic bed (on one side) and the thruster valve (on the other side). The thruster valve presently used for the experimentation is a commercial solenoid valve able to provide a response time of no more than 20 milliseconds.

\section{E. Sensors and Transducers}

The sensor used for static pressure measurements at the inlet and outlet of the catalytic bed is an absolute pressure transducer produced by Kulite, model XTM-190M-17 bar A. It has been chosen for its good precision (its accuracy is $1 \%$ FSO) and the miniaturized dimensions, which give the possibility of installing it without problems in the very small prototype thrusters.

Temperature measurements are carried out by means of K-type thermocouples with $0.5 \mathrm{~mm}$ diameter and 150 mm length, produced by TC Direct in the United Kingdom. They are miniature, mineral-insulated thermocouples, ideal for demanding precision temperature measurements due to the response, size, displacement and robustness of the assembly.

The thrust is measured by a compression load cell produced by Sensotec (model 13), with an accuracy of $0.9 \%$ FSO. The propellant flow rate, on the other hand, is measured by a Coriolis mass flow meter, Krohne model Optimass MFS 7100 S04, having an accuracy of $0.1 \%$ of the measured value.

Finally, the pressure oscillations at the catalytic bed outlet are measured by means of a piezoelectric pressure transducer produced by PCB Piezotronics, model M105C02. This is a miniaturized dynamic pressure transducer based on ICP electrical standards, with a sensitivity of $50 \mathrm{mV} / \mathrm{psi}$ and a maximum error less than $2 \%$ FS. Considering that this transducer is not able to sustain particularly high temperatures (its maximum operating temperature is $121^{\circ} \mathrm{C}$ ), a recessed mounting has been chosen: the measurement port is significantly far from the gas flow, and the transducer is installed in an appropriately designed connector, brazed on the catalytic bed body. A very small flow of liquid propellant is spilled from the inlet pressure measurement port and fills the measuring line, in order to make it incompressible and to avoid the cut-off of measurable frequencies which would be observed if the line were filled with compressible gas. 

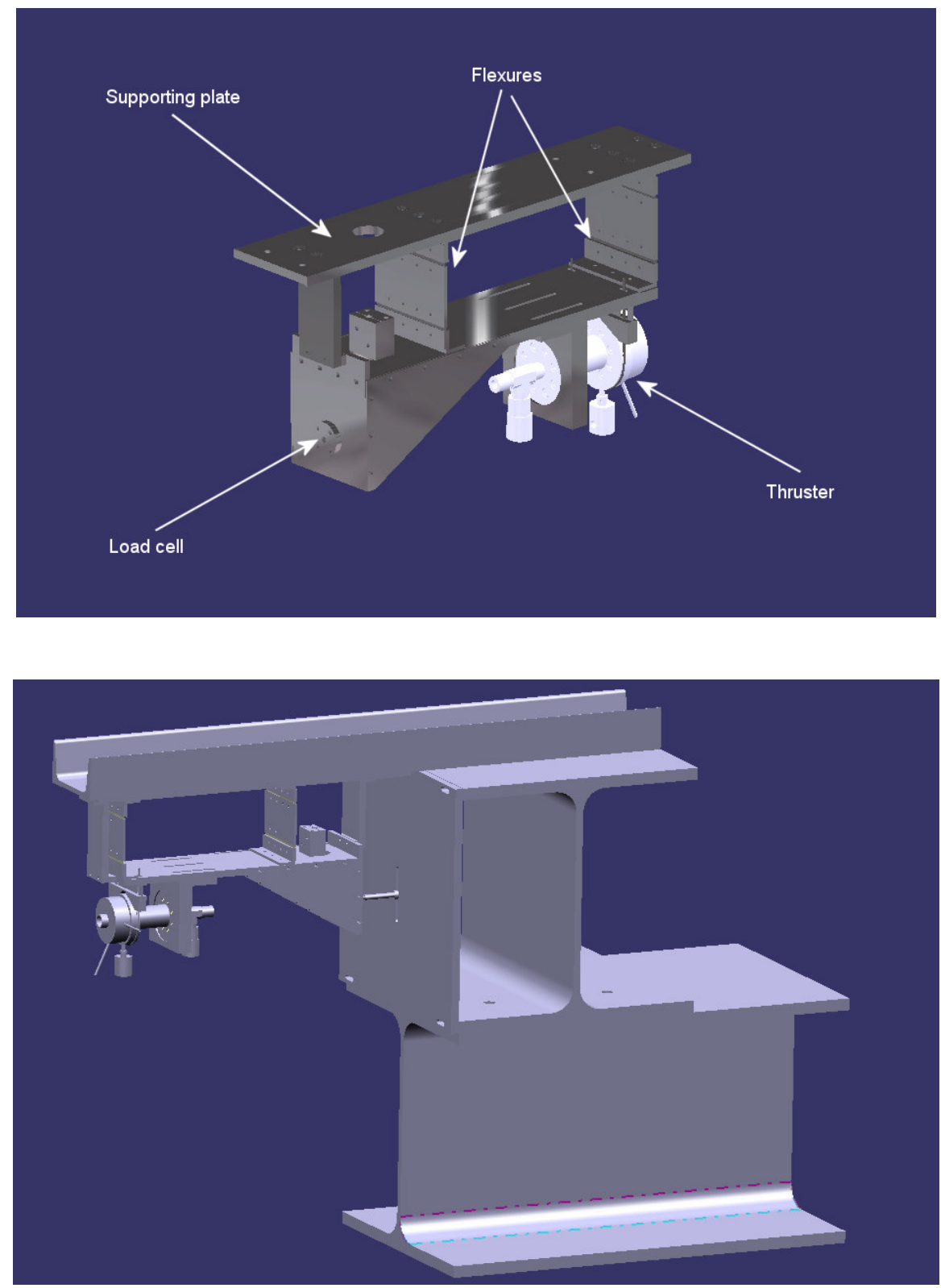

Figure 3. Three-Dimensional Model of the Alta S.p.A. Test Bench (top) and Supporting Structure (Bottom)

\section{Test Bench}

Three-dimensional sketches of the test bench are presented in Figure 3. The thruster is installed, by means of suitably designed interfaces, on a structure to which is fitted the load cell for the measurement of thrust. A supporting plate gives the possibility of interfacing the test bench with the supporting structure, made by sufficiently stiff and heavy C- and I- beams. A plate installed on the upper I-beam of the supporting structure is used as the matching element for the compression load cell.

Two flexures, made of thin, stainless steel sheets (with a thickness between 0.2 and $0.5 \mathrm{~mm}$ ), are used for transferring to the supporting structure all the off-axis loads. A series of holes and connections for the hydrogen peroxide supply tubes has also been incorporated into the design. The characteristics of these connections have been 
chosen in order to supply the propellant to the test thruster without introducing undesired additional forces in the same direction of the thrust.

In addition to this test bench, a propellant supply plant has been specifically designed for providing hydrogen peroxide to the prototype thrusters. This supply facility is intended as a multi-purpose one, which can be easily adapted and reconfigured for tests on thrusters with different characteristics (like bi-propellant or hybrids) and different target performance. A schematic of the facility is given in Figure 4.

The propellant is stored in a small main tank with a volume of about 2.5 liters. Considering that highconcentration hydrogen peroxide has to be stored in the tank, it is made of stainless steel internally coated with Teflon. If higher quantities of propellant are necessary for the tests (as in the case of larger test engines), this tank can be connected to a larger one, which is capable of storing the required amount of propellant. The tank is connected to three different types of safety equipment: a manually operated valve, a burst-disk and a non-return valve. A pressure transducer and a thermocouple give continuous indications of pressure and temperature of the hydrogen peroxide stored in the tank.

The mass flow rate of hydrogen peroxide in the ducts is regulated with the required precision by means of a calibrated cavitating Venturi, and measured using the Coriolis mass flow meter. One absolute and one differential pressure transducer provide an indication of the actual behavior of the cavitating Venturi in terms of pressure losses. Remotely-operated electro-pneumatic valves are used for opening and closing the branches of the facility. Gaseous nitrogen (or another inert gas) on three different gas lines is used for pressurizing the propellant, activating the pneumatic valves and venting/cleaning the ducts from propellant residuals.

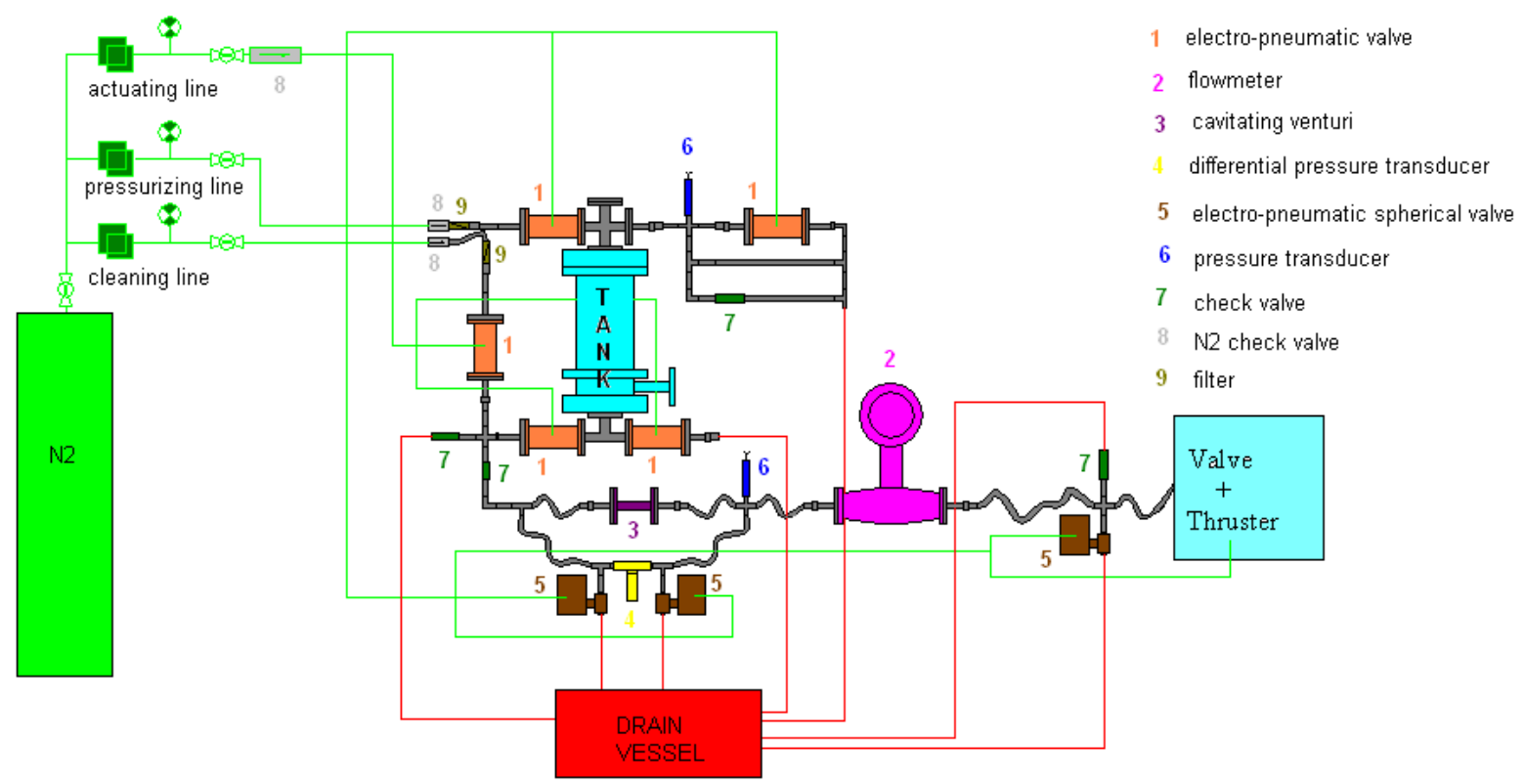

Figure 4. Schematic of the hydrogen peroxide supply facility.

\section{Preliminary Test Schedule}

A preliminary test schedule has been prepared, based on the possibility of testing several different catalytic bed configurations (at least for the $5 \mathrm{~N}$ prototype) in order to compare their performance with sufficient accuracy in a complete test campaign. The following tests are foreseen:

- First test campaign on the $5 \mathrm{~N}$ prototype thruster. According to the lower value of the mass flow rate, this configuration gives the possibility of carrying out tests for significantly longer times. For this reason, preliminary tests on several different catalytic bed configurations (using silver grids or manganese oxidecovered or platinum-covered pellets) have been foreseen. Tests under design conditions, including firings with different impulse lengths and repetitions of several short impulses, will be carried out. After having selected one 
most promising solution among these candidate catalyst configurations, a more intensive set of tests on a new catalytic bed based on the chosen solution has been scheduled. Some "off-design" tests (i.e. at different values of mass flow rate and/or pressure with respect to the nominal ones) have also been scheduled on the selected catalytic bed configuration.

- Second test campaign on the $25 \mathrm{~N}$ prototype thruster. In this case, two different catalytic bed configurations (one using silver grids, the other using an alternative solution like manganese oxide-covered or platinumcovered pellets) will be tested. A complete set of tests for each one of these configurations has been scheduled. Some "off-design" tests have also been scheduled for this case.

\section{Conclusions and way forward}

Two hydrogen peroxide monopropellant thrusters (a $5 \mathrm{~N}$ and a $25 \mathrm{~N}$ one) have been designed by Alta S.p.A. (Italy) and DELTACAT Ltd. (UK) in the framework of an activity funded by the European Space Agency. These prototype thrusters are based on advanced catalytic beds (silver grids, manganese oxide or platinum covered pellets) and will be tested in a dedicated test bench at Alta S.p.A. Tests will focus on the comparison of several catalytic bed configurations by means of thrust, pressure (static and dynamic) and temperature measurements. The final objective of the activity is the identification of a catalytic bed configuration and thruster design to be further developed at an industrial stage.

The components of the prototype thrusters and the test bench are presently under realization. The testing phase is scheduled to commence in July 2006.

\section{Acknowledgments}

The present Alta/DELTACAT joint activity on hydrogen peroxide monopropellant thrusters has been funded by ESA-ESTEC in the framework of the LET-SME program.

The authors would like to express their gratitude to Profs. Mariano Andrenucci, Fabrizio Paganucci and Renzo Lazzeretti of the Dipartimento di Ingegneria Aerospaziale, Università di Pisa, for their constant and friendly encouragement, and to Angelo Pasini, Antonio D'Elia, Luca Romeo and other students who have participated in various aspects of the project.

\section{References}

${ }^{1}$ Wucherer E. J., Christofferson S. and Reed B., 2000, “Assessment of High Performance HAN Monopropellants”, AIAA paper n. 2000-3872, 36th AIAA/ASME/SAE/ASEE Joint Propulsion Conference, Huntsville, Alabama.

${ }^{2}$ Schoyer H.F.R., Korting P.A.O.G., Veltmans W.H.M., Louwers J., v.d. Heijden A.E.D.M., Keizers H.L.J. and v.d. Berg R.P., 2000, "An Overview of the Development of HNF and HNF-based Propellants", AIAA paper n. 2000 - 3184, 36th AIAA/ASME/SAE/ASEE Joint Propulsion Conference, Huntsville, Alabama.

${ }^{3}$ Ventura M. and Mullens P., 1999, “The Use of Hydrogen Peroxide for Propulsion and Power”, AIAA paper n. 99-2880, 35th AIAA/ASME/SAE/ASEE Joint Propulsion Conference, Los Angeles, California.

${ }^{4}$ Wernimont E. and Mullens P., 1999, "Recent Developments in Hydrogen Peroxide Monopropellant Devices", AIAA paper n. 99-2741, 35th AIAA/ASME/SAE/ASEE Joint Propulsion Conference, Los Angeles, California.

${ }^{5}$ Wernimont E. and Garboden G., 1999, "Experimentation with Hydrogen Peroxide Oxidized Rockets", AIAA paper n. 992743, 35th AIAA/ASME/SAE/ASEE Joint Propulsion Conference, Los Angeles, California.

${ }^{6}$ Musker A. J., 2003, "Highly Stabilised Hydrogen Peroxide as a Rocket Propellant", AIAA paper n. 03-4619, 39th AIAA/ASME/SAE/ASEE Joint Propulsion Conference, Huntsville, Alabama.

${ }^{7}$ Walter H., 1956, Hydrogen Peroxide Rockets, in "History of German Guided Missile Developments", ed. Benecke, T and Quick, A.W., AGARDograph No.20.

${ }^{8}$ Runckel J. F., Willis C.M., Salters Jr. L. B., 1963, “Investigation of Catalyst Beds for 98-Percent-Concentration Hydrogen Peroxide", NASA TN D-1808, Langley Research Center, Hampton, Virginia.

${ }^{9}$ Willis C. M., 1960, "The Effect Of Catalyst-Bed Arrangement On Thrust Buildup And Decay Time For A 90 Percent Hydrogen Peroxide Control Rocket”, NASA TN D-516.

10 Rothmund C., Harlow J., 1999, "A History of European Liquid-Propellant Rocket Engines for Aircraft", 35th AIAA/ASME/SAE/ASEE Joint Propulsion Conference, Los Angeles, California.

${ }^{11}$ Sellers J., Brown R., Paul M., 1998, "Practical Experience with Hydrogen Peroxide Catalysts", $1^{\text {st }}$ International Hydrogen Peroxide Propulsion Conference, University of Surrey, UK.

${ }^{12}$ Whitehead J., 1998, "Hydrogen Peroxide Propulsion for Smaller Satellites", $1^{\text {st }}$ International Hydrogen Peroxide Propulsion Conference, University of Surrey, UK. 
${ }^{13}$ Ventura M., Wernimont E., 2001, “Advancements in High Concentration Hydrogen Peroxide Catalytic Beds”, AIAA paper n. 01-3250, 37th AIAA/ASME/SAE/ASEE Joint Propulsion Conference, Salt Lake City, Utah.

${ }^{14}$ Iarochenko N., Dedic V., 2001, "Hydrogen Peroxide as Monopropellant - Catalysts and Catalyst beds - Experience from more than Thirty Years of Exploitation", $1^{\text {st }}$ International Conference on Green Propellants for Space Propulsion, European Space Agency, Noordwijk, Holland, ISBN 92 9092-771-1.

${ }^{15}$ Wu P.K., Fuller R.P., Morlan P.W., Ruttle D.W., Nejad A.S., Anderson W.E., 1999, "Development of a Pressure-Fed Rocket Engine Using Hydrogen Peroxide and JP-8", AIAA paper n. 99-2877, 35th AIAA/ASME/SAE/ASEE Joint Propulsion Conference, Los Angeles, California.

${ }^{16}$ Musker A. J., Roberts G., Chandler P., Grayson J., Holdsworth J., 2004, "Optimisation Study of a Homogeneously-Catalysed HTP Rocket Engine", $2^{\text {nd }}$ International Conference on Green Propellants for Space Propulsion, Chia Laguna, Italy.

${ }^{17}$ Bramanti C., Cervone A., d'Agostino L., 2005, "Assessment of the Propulsive Performance of Fuel Vapor Pressurized Hydrogen Peroxide-Ethane Rocket Engines”, XVIII Congresso Nazionale AIDAA, Volterra, Italy. 